\title{
Ginástica expressiva
}

José RafaelMadureira *

[BODE, Rudolf. Ginástica expressiva. New York: A. S. Barnes

\& Company, 1931. 161 p.]

A obra Ginástica expressiva (Ausdrucksgymnastik) ${ }^{1}$ foi publicada pela primeira vez em 1922, num momento histórico de profusa invenção de métodos e sistemas de educação corporal, ginástica e dança. A obra destaca-se pelas instigantes idéias apresentadas por Rudolf Bode, seu autor, cujos pensamentos seguramente nortearam a formação de muitas gerações de dançarinos e de pedagogos do corpo na Europa, nos Estados Unidos e, de modo indireto, no Brasil, levando-se em consideração a ausência de uma versão em português.

A obra Ginástica Expressiva pode ser lida como um clássico da literatura específica relacionada à história das práticas corporais, suas origens e permanências. Rudolf Steiner, Jaques-Dalcroze e Rudolf Bode desenvolveram, cada qual à sua maneira, uma ginástica "corretiva" fundamentada no ritmo "natural" da criança. A eurritmia, termo empregado pelos três autores, contrapōe-se à arritmia de uma sociedade marcada por um violento descompasso entre a organicidade do corpo e os modos socioeconômicos de produção. Todos eles rememoram em uníssono os áureos tempos da República de Platão e os preceitos éticos e estéticos da Paidéia, cujos sólidos alicerces se apoiavam na gramática, na música e na ginástica.

As investigaçôes do compositor ${ }^{2}$ e pedagogo alemão Rudolf Bode (18811971) estavam centradas na recuperação da "organicidade do corpo", numa

\footnotetext{
* Doutorando em Educação, Linguagem e Arte no Programa de Pós-Graduação em Educação da Faculdade de Educação da Universidade Estadual de Campinas (Unicamp), SP. Brasil. rafadanse@hotmail.com

1. Utilizei a tradução em inglês intitulada Expression-Gymnastics, realizada por Sonya Forthal e Elizabeth Waterman, que se encontra disponível no acervo da Faculdade de Educação Física da Unicamp.

Agradeço à Maria Fernanda Faigle pelas correçōes e sugestōes apresentadas ao longo deste texto e também pela minuciosa revisão das traduçōes.

2. Nos domínios da composição, RudolfBode publicou uma obra musical especialmente destinada à prática da ginástica expressiva e da ginástica rítmica: Musik und Bewegung: Kioviermusik für
} 
tentativa de libertar a criança-sociedade da morbidez escolástica, responsável pela paralisia do corpo e, consequientemente, pela destruição do homem:

O homem civilizado de hoje trabalha e movimenta-se com a total exclusão do tronco. Somente nos artesãos e nos camponeses podemos observar os movimentos do trabalho realizados corretamente. A inteireza dos movimentos naturais só pode ser observada nos animais e nas crianças antes de freqüentarem a escola. Depois de poucos anos de escola a naturalidade é suprimida de praticamente todas as crianças. Permanecer por horas sentado nas carteiras escolares, torturado pelas liçóes de ortografia com as severas restriçóes das mãos e braços e realizar a leitura de textos e do material didático tem um incrível poder paralisante. O que se perde não é o movimento, mas a vitalidade essencial do movimento, a secreta composição entre a alma e o corpo (Bode, Expression-Gymnastics, p. 52-53).

Os questionamentos apresentados em Ginástica expressiva apontam para o despertar de uma nova compreensão do valor das práticas corporais na formação da criança. Os harmoniosos e expressivos movimentos propostos em Ginástica expressiva, uma espécie de dança, são nostalgicamente inspirados na antigüidade e contrapõem-se à retidão dos sistemas ginásticos militares e esportivos em voga naquele momento.

A dança verdadeira não é uma espécie de esporte refinado, mas exatamente o seu contrário. Entre o esporte e a dança encontrase a ginástica expressiva, pois contém ambos os componentes, a estimulação dos sentimentos e a expressão da vontade. A chamada dança artística que atualmente observamos encenada não pode ser entendida como dança. Na maioria dos casos, realizase como uma ginástica de má qualidade (Bode, ExpressionGymnastics, p. 42-43).

$\mathrm{Na}$ concepção da ginástica expressiva, mover-se é tão natural quanto respirar, falar, cantar, andar, não sendo necessário impor ao corpo um tecnicismo desprovido de sentido.

Apoiado numa experiência de muitos anos eu não posso deixar de advertir sobre o uso exagerado da técnica na Educação Física. O corpo não é um instrumento da vontade! Um conhecimento técnico que não esteja a serviço da expressão do espírito destrói os sentimentos vitais e, conseqüientemente, a possibilidade de interpretaçóes criativas. Com muita frequiência, a ausência de uma verdadeira expressividade precisa ser preenchida pela técnica (Bode, Expression-Gymnastics, p. 43). 
Rudolf Bode desenvolveu a Ginástica Expressiva inspirado no sistema expressivo de educação do gesto desenvolvido por François Delsarte (1811-1871). Ao instituir a denominada "unidade orgânica" (CORPO-MENTE-ALMA), Bode recupera a Lei da Trindade, axioma central da teoria delsartiana da expressão (Estética Aplicada).

A partir da idéia de que toda experiência emocional é uma experiência de totalidade, nossa vida emocional reage especialmente na totalidade dos movimentos corporais. Todas as formas de ginástica que não se aplicarem sobre a totalidade dos movimentos corporais incorrerão no mesmo perigo que um esporte centrado apenas nos resultados de pontuação. Desse modo, o organismo vivo tornar-se-á um mecanismo morto (Bode, Expression-Gymnastics, p. 42).

Ainda que Rudolf Bode questione os ensinamentos de Jaques-Dalcroze ${ }^{3}$, as liçôes de Rítmica, recebidas no Instituto de Hellerau ${ }^{4}$, foram decisivas no devir da ginástica expressiva e na compreensão da relação intrínseca estabelecida entre a música e a expressividade do corpo (Langlade. Teoría general de gimnasia, p. 87). Ao afirmar que "todo movimento possui um caráter contínuo e rítmico" (p. 11), Bode revela inequívocos traços de sua filiação dalcroziana.

A obra Ginástica expressiva, dividida em duas partes, carrega substanciosas reflexôes, todavia atuais, sobre as sem-razōes da hegemonia esportiva na educação da sociedade. Em consonância com essas idéias, Jaques-Dalcroze irá afirmar:

Se eu aprovo que os jovens cultivem o esporte, eu detesto aqueles cuja única preocupação é desenvolver suas faculdades físicas com o único objetivo de participar de competiçóes. Eu conheço quem se interesse por lutas, tênis e corridas, mas que é incapaz de conversar sobre outro assunto (Jaques-Dalcroze, Notes bariolées, p. 65-66).

Gymnastik und Gruppenrhythmik (Música e movimento: peças para piano destinadas à prática da ginástica e aos exercícios de rítmica em grupo). Munique: C. H. Beck'sche Verlagsbuchhandlung München, 1931 ( 6 volumes).

3. "O uso do metrônomo, empregado para determinar o sentido rítmico nos laboratórios de psicologia esportiva, deve-se à carência de uma compreensão da natureza do ritmo. O mesmo equívoco fundamental prevalece no método rítmico de Jaques-Dalcroze, que não deveria absolutamente ser chamado ginástica rítmica" (Bode, Expression-Gymnastics, p. 39).

4. O "Bildunganstand für Musik und Rhythmus Jaques-Dalcroze" foi inaugurado no bairro-jardim de Hellerau (Dresden, Alemanha) em | 91 | e funcionou até a eclosão da Primeira Guerra Mundial como centro da vanguarda artística novecentista. Rudolf Bode recebeu o certificado de "Rythmicien", tornando-se habilitado para ministrar liçōes da Rítmica Jaques-Dal croze. 
Se a educação for essencialmente esportiva, ela ultrapassará o seu objetivo e engendrará geraçôes inteiras desprovidas de sensibilidade (Jaques-Dalcroze, L’école, la musique et la joie, p. 95).

Na primeira seção de Ginástica expressiva, Rudolf Bode apresenta os fundamentos estético-filosóficos de um sistema corporal orientado para a formação de uma nova identidade nacional. Ao longo do texto, nomeia os seus inspiradores: Rousseau, Thiele, Nietzsche e, com especial deferimento, Pestalozzi. Logo nas primeiras páginas, Bode esboça uma vigorosa reação contra os descaminhos do esporte moderno conduzido pelo capcioso adágio "Altius, citius, fortius" (de maneira mais alta, mais rápida e mais forte).

Se o esporte quebrou as correntes com as quais a velha, restrita e convencional Educação Física se desenvolveu desde a original idéia deixada por Jahn, que também almejou o movimento livre, ele se encontra agora em perigo, arriscando-se a sacrificar esse movimento livre por enfatizar e buscar unicamente pontuaçóes elevadas e a quebra de recordes. Vozes de alerta já foram ouvidas sobre a degeneração do esporte na Inglaterra e nos Estados Unidos, onde a busca desenfreada por novos recordes revela consequiências dramáticas que têm colocado $\mathrm{em}$ xeque todo o valor da Educação Física. É evidente que a competição é necessária e certamente ninguém deseja desfazer-se dela. Mas a competição realizada com oponentes animados é algo muito diferente de um mero jogo com figuras inertes. As naçôes que detêm os recordes mundiais são realmente as melhores? A habilidade de suprimir todo movimento natural e livre com o único propósito de mecanizar os movimentos é realmente um sinal de superação da força da vontade? [...] Devemos subordinar a vivacidade do movimento humano, presente nesse sistema de Educação Física, à morbidez dos movimentos calcados na busca obsessiva pela quebra de recordes? $A$ Educação Física é a supressão ou desenvolvimento do movimento original? Pestalozzi já respondeu a essa questão (Bode, ExpressionGymnastics, p. 9-10, grifos do autor).

É preciso enfatizar que nós não desaprovamos o recorde em si mesmo, mas nós de fato reprovamos uma Educação Física fundamentada unicamente no culto ao recorde e na ênfase restrita ao placar mais elevado (Bode, Expression-Gymnastics, p. 26-27).

Na seção seguinte, os exercícios de ginástica expressiva são detalhadamente descritos, conduzidos a partir de três pressupostos: “1) ter a habilidade de relaxar a musculatura; 2) ter a habilidade de ajustar o impulso na base do centro de gravidade; 3) ter a habilidade de efetuar o movimento do centro do corpo para a extremidade." (Bode, Expression-Gymnastics, p. 50). 
A última parte da obra é amplamente ilustrada com 48 fotografias em preto e branco que, nas "entrelinhas" do discurso visual, narram a perigosa ideologia de uma ginástica "pura" (Reinegymnastik), exibindo corpos jovens (de ambos os sexos), magros, musculosos, quase nus, retratados ao ar livre, no campo ou à beira-mar; corpos "in natura", supostamente desprovidos de vícios, de historicidade ou de memória. Por conseguinte, a ginástica expressiva foi amplamente empregada no programa estético-político do Nationalsozialismus, que encontrou no aprimoramento físico e racial o seu carro-chefe.

Rudolf Bode insiste na completa emancipação da educação física dos grilhôes da anatomia e da fisiologia que, por desprezarem a dimensão sociocultural do homem, comprometem o verdadeiro entendimento do corpo e dos seus mecanismos expressivos.

Muitos professores de Educação Física têm a inclinação de tomar a anatomia e a fisiologia como base dos exercícios físicos. Eles também acreditam que a estrutura anatômica do corpo ou os processos fisiológicos do movimento devem conduzir a estruturação dos exercícios físicos. A ciência é incapaz de descrever um simples movimento natural ou mesmo de organizar um exercício baseado no movimento natural. Esse fato vem sendo contínua e lentamente reconhecido pelos profissionais da nossa área (Bode, Expression-Gymnastics, p. 28)

Um sistema de ginástica fundamentado na anatomia nunca poderá ser considerado suficiente para o desenvolvimento da forma orgânica. Mesmo o maior conhecimento em anatomia não poderá ajudar, pois não existe um único músculo que tenha a mesma forma $\mathrm{cm}$ dois indivíduos (Bode, ExpressionGymnastics, p. 29-30).

A teoria na qual a anatomia $\mathrm{c}$ a fisiologia fundamentam os sistemas práticos de Educação Física tem origem no caráter mecanicista das últimas décadas, que compreende o corpo humano apenas como uma máquina (p. 32).

Ao contrário do que se possa imaginar, a obra Ginástica expressiva pode ser recuperada como uma vigorosa resistência contra uma certa cultura fitness ou cultura da "malhação" que, atualizada num demagógico discurso pela "saúde e qualidade de vida”, mantém acesa a pira olímpica do fascismo. Rudolf Bode, por fim, não negligencia a imprescindível presença do mestre na transmissão dos saberes do corpo, apostando numa imemorial tradição oral: "A ginástica expressiva revela o seu caráter nas trocas estabelecidas entre o professor e seu discípulo. Sua vitalidade não pode ser apresentada em letras" (Bode, ExpressionGymnastics, p. 59-60). 
Referências bibliográficas

JAQUES-DALCROZE, Emile. Notes bariolées. Genève/Paris: Jeheber, 1948.

JAQUES-DALCROZE, Emile. L'école, la musique et la joie (1915) In: Le rythme, la musique et l'Éducation. Lausanne: Edition Fxtisch, 1965.

LANGLADE, Alberto; LANGLADE, Nelly Rey de. Teoria general de la gimnasia. 2.ed. Buenos Aires: Stadium, 1982. 